\title{
Southeastern United States Observations of Stormwater Pollutant Strengths by Particle Size
}

\author{
Robert Pitt, ${ }^{1}$ Shirley E. Clark, ${ }^{2}$ Yezhao Cai, ${ }^{3}$ Renee Morquecho ${ }^{4}$ and Jejal Reddy Bathi ${ }^{5}$ \\ ${ }^{1}$ University of Alabama, Tuscaloosa, Alabama; ${ }^{2}$ Penn State Harrisburg, Middletown, Pennsylvania; ${ }^{3}$ Planners \& Engineers Collaborative, Inc., \\ Atlanta, Georgia; ${ }^{4}$ Indian Wells Valley Water District, Ridgecrest, California; ${ }^{5}$ Global Systems International, LLC, Chattanooga, \\ Tennessee.
}

\begin{abstract}
This paper summarizes the results of several stormwater research projects that investigated particulate pollutant strengths for different particle size ranges. This paper builds on the previous paper simultaneously published describing particle size distributions of stormwater particulates (Pitt et al. 2016). The pollutant strength information presented in this paper, along with the particle size distribution in the other paper, is critical when understanding the routing of stormwater particulates through urban systems and especially when calculating the expected performance of stormwater controls. The pollutant concentrations commonly have a bimodal distribution, with higher values for small particles (due to large surface areas) and sometimes for large particles (such as for polycyclic aromatic hydrocarbons, PAHs, that are strongly associated with large organic debris). In most cases, the majority of the stormwater pollutant masses at outfalls are associated with small and moderate-sized particulates (usually from $\sim 10 \mu \mathrm{m}$ to $200 \mu \mathrm{m}$ ) which are effectively transported through drainage systems. Stormwater controls that focus on larger particles (such as $>300 \mu \mathrm{m}$ ) that are more abundant at source areas may have less effective benefits on discharged stormwater quality as they only contribute small fractions of the total particulate mass after being poorly transported through most drainage systems. Treatability tests show that effective removal of particulate-bound stormwater pollutants requires the control of the small particles, usually down to $\sim 10 \mu \mathrm{m}$ in size. Pre-treatment stormwater controls that focus on larger particles reduce maintenance issues and provide other benefits, but need to be supplemented with additional controls that are effective in the removal of small particles, usually in a treatment train arrangement.
\end{abstract}

\section{Introduction}

Knowing the distribution of pollutants associated with different sized stormwater particles allows more accurate determinations of their sources, transport, and control. Urban stormwater quality models can use this information when routing stormwater particulate-bound pollutants from their source areas and then through the drainage system and stormwater controls. The discharged particle size distributions and associated pollutants can then be used in receiving water models to calculate their fates and effects.

Pollutant strengths are the contaminant concentrations associated with the particulate matter in the stormwater. As such, these values can be used to help identify sources of these contaminants, based on their similar values to particulates found within the watershed (fingerprinting). Particulate strengths are determined by calculating the pollutant concentration only associated with the particulates (measured as total suspended solids, TSS, or suspended sediment concentration, SSC, depending on how the sample was collected and analyzed) in the runoff water. They are calculated by the following equation:

$$
\frac{\text { total conc. - filterable conc. }}{\text { particulate solids conc. }}
$$

As an example, if the total copper concentration in the stormwater was $50 \mu \mathrm{g} / \mathrm{L}$, the filterable (dissolved) copper concentration was $10 \mu \mathrm{g} / \mathrm{L}$, and the TSS concentration was $150 \mathrm{mg} / \mathrm{L}$, the particulate strength for this sample would be:

$$
\begin{aligned}
& (50 \mu \mathrm{g} \mathrm{Cu} / \mathrm{L}-10 \mu \mathrm{g} \mathrm{Cu} / \mathrm{L}) \div(150 \mathrm{mg} / \mathrm{L}) \\
& \quad=0.26 \mu \mathrm{g} \mathrm{Cu} / \mathrm{mg} \text { solids } \\
& \quad=260 \mu \mathrm{g} \mathrm{Cu} / \mathrm{g} \text { particulate solids } \\
& =260 \mathrm{mg} \mathrm{Cu} / \mathrm{kg} \text { particulate solids } \\
& \text { (also }=260 \mathrm{ppm} \text {, the usual units for soil analyses). }
\end{aligned}
$$

This value is therefore the pollutant concentration associated with the particulate matter in the runoff sample. These values are very useful when identifying erosion and other sources of the particulate-bound pollutants in the runoff, in contrast to the $\mu \mathrm{g} / \mathrm{L}$

Pitt, Robert, Shirley E. Clark, Yezhao Cai, Renee Morquecho and Jejal Reddy Bathi. 2017. Southeastern United States Observations of Stormwater Pollutant Strengths by Particle Size. Journal of Water Management Modeling 25:C418.

https://doi.org/10.14796/JWMM.C418 c CHI 2017. www.chijournal.org ISSN 2292-6062. 
concentration values that are affected by dilution and site hydrology. As an example, the particulate strength data presented in this paper for outfall samples can be compared to typical particulate strength data for watershed soils and source area dust and dirt along with dry atmospheric deposition material. Pitt, Bannerman et al. (2005a; 2005b) and Pitt, Williamson et al. (2005) previously summarized particulate strength (and sheetflow quality) for many urban sources, showing how these values vary in urban areas based on land use and site activities.

\section{Pollutant Strengths by Particle Size}

As for all constituents and characteristics, the total particulate strength of stormwater particulates is determined by the amount of each component in the final mixture, along with the characteristics of each particle size range. This particle size range information is also very useful when predicting the performance and design of stormwater controls. Particle size distributions (PSDs) of stormwater particulates were discussed in the companion paper published along with this paper (Pitt et al. 2016). The following are brief summaries of data from several research projects carried out by the stormwater research laboratories at the University of Alabama (Department of Civil, Construction and Environmental Engineering), and associates, that have examined stormwater particulate characteristics by particle size.

An example of sample collection and processing is demonstrated by a recent study in Tuscaloosa, Alabama. In a stormwater treatability study at an urban parking lot, Cai (2015) collected composite samples in high density polyethylene bottles from the influent and effluent locations of the treatment controls. After each targeted storm event, the samples were brought to the laboratory as soon as possible and either cooled in a sample refrigerator or immediately processed. Composite samples were split evenly into ten $1 \mathrm{~L}$ bottles using a USGS/Dekaport Teflon cone splitter. Nylon screening material with $1180 \mu$ m openings was placed on top of the cone splitter to capture larger particles and debris to prevent clogging of the cone splitter and to capture and analyze this large material. The different steps involved in the sample processing and water quality analyses were as shown in Figure 1. Suspended solids concentrations (SSC) were analyzed in accordance with ASTM D 3977-97B. One of the influent sample splits for each event was screened through three different sieves and one filter for analyses of pollutant associations with different particle size ranges. The measured total volume of each subsample was used for the SSC and PSD analyses. Particle size distributions were determined in a multi-step procedure using screening (>1 $180 \mu \mathrm{m})$, sieving (250 $\mu \mathrm{m}$ to $1180 \mu \mathrm{m})$ and filtering (0.45 $\mu \mathrm{m}$ to $3 \mu \mathrm{m}$ ), followed with Coulter Counter analyses ( $3 \mu \mathrm{m}$ to $250 \mu \mathrm{m}$ ). Metals were analyzed in accordance with the EPA 200.7 method. After dividing the samples into particle size ranges, each sample fraction was analyzed for various constituents and properties.

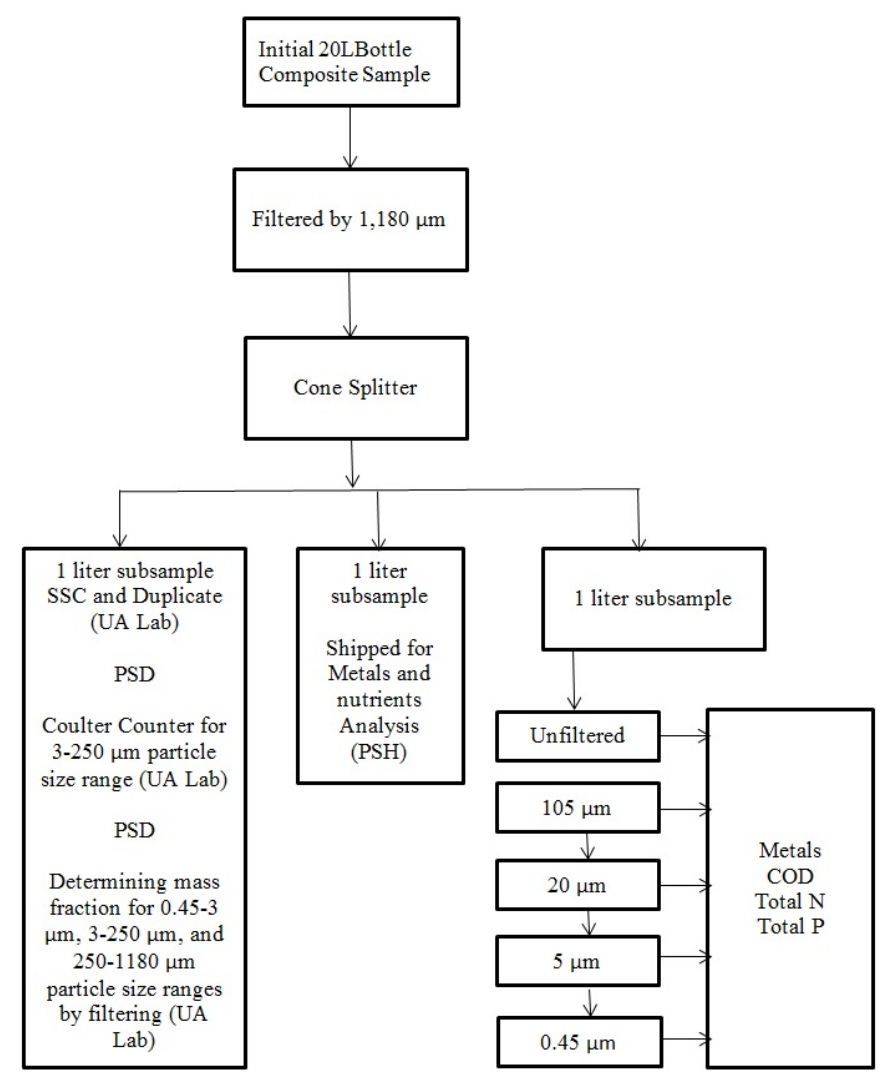

Figure 1 Flowchart showing steps of sample processing and water quality analyses (Cai 2015).

\subsection{Specific Gravity of Stormwater Particles}

Bulk density of stormwater particulates was determined by analyzing collected sediment from stormwater control devices (Cai 2015). This material was air dried and then sieved into separate particle size ranges. Dried and separated sediment were then placed in a graduated cylinder to a known volume, with moderate compaction. The material was then weighed in the cylinder and after subtracting the tare weight of the cylinder, the bulk density can be calculated. The specific gravity can then be calculated after the void ratio is determined. The void ratio was determined by slowly pouring clean water (having a very small amount of detergent to act as a wetting agent) into the cylinder until the sediment sample is saturated. The amount of water added equals the void volume of the sample. This process allows bulk density and specific gravity to be determined for different size ranges. In order to determine the specific gravity of small size particles in the stormwater, the Coulter Counter volume values and particle counts are used for the particle sizes of interest. These are verified from the gravimetric solids analyses of the stormwater samples.

In a stormwater treatability study at an urban parking lot, Cai (2015) collected composite samples at the influent and effluent for an upflow treatment system at a parking lot in Tuscaloosa, Alabama. This was a complete mass balance analysis, so captured sediment was also evaluated. Table 1 shows the average specific 
gravity and volatile solids of the captured material for different size ranges.

Table 1 Specific gravity and volatile solids for different size fractions in the sediment of a stormwater control device (Cai 2015).

\begin{tabular}{lcc}
\hline \multicolumn{1}{c}{ Sieve size range (um) } & Average Specific Gravity $(\mathrm{g} / \mathrm{cc})$ & Average Volatile Solids (\%) \\
\hline Large Organic Material & 0.84 & 81.2 \\
$>2800$ & 0.66 & 70.9 \\
$1400-2800$ & 1.15 & 57.8 \\
$710-1400$ & 1.43 & 42.7 \\
$355-710$ & 2.56 & 26.1 \\
$180-355$ & 2.76 & 19.4 \\
$75-180$ & 2.97 & 20.6 \\
$45-75$ & 3.30 & 25.7 \\
$<45$ (Pan) & 3.46 & 26.0 \\
\hline
\end{tabular}

Specific gravity decreases as the volatile solids content increases; larger particle sizes have lower specific gravity and greater volatile solids as they contain larger amounts of light-weight organic debris. Figure 2 is a plot of the specific gravity values for the influent and effluent stormwater for this site for 30 monitored events.

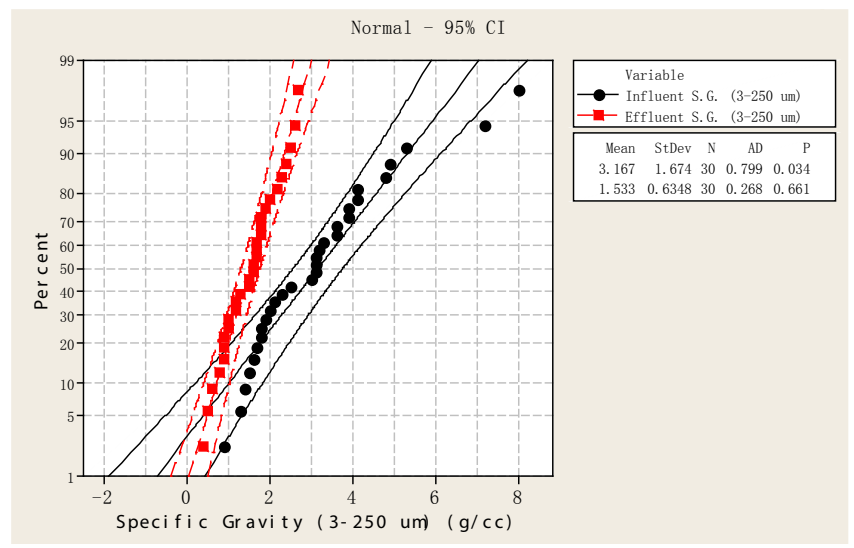

Figure 2 Changes in specific gravity with sedimentation and media filtration treatment (Cai 2015).

This figure shows the preferential removal of higher specific gravity materials that result in a shift to a lower overall specific gravity of particulates in the effluent water (and greater migration distance in receiving water after discharge before sedimentation). The median specific gravity in the influent is $3.2 \mathrm{~g} / \mathrm{cc}$, while it dropped to $1.5 \mathrm{~g} / \mathrm{cc}$ for the treated effluent. The probability plots show a wide range of specific gravities (about $1.3 \mathrm{~g} / \mathrm{cc}$ to $6 \mathrm{~g} / \mathrm{cc}$ for the 5 th percentile to the 95 th percentiles).

\subsection{Chemical Oxygen Demand and Nutrients}

Figure 3 shows the results of total phosphorus for fourteen urban residential and commercial area sheetflow samples analyzed by Morquecho (2005). The general trend is a decrease in overall concentration as finer and finer particles are removed. After about $10 \mu \mathrm{m}$, it appears that no more particulate-bound phosphorus was being removed and that the remaining phosphorus concentration is all in dissolved forms.

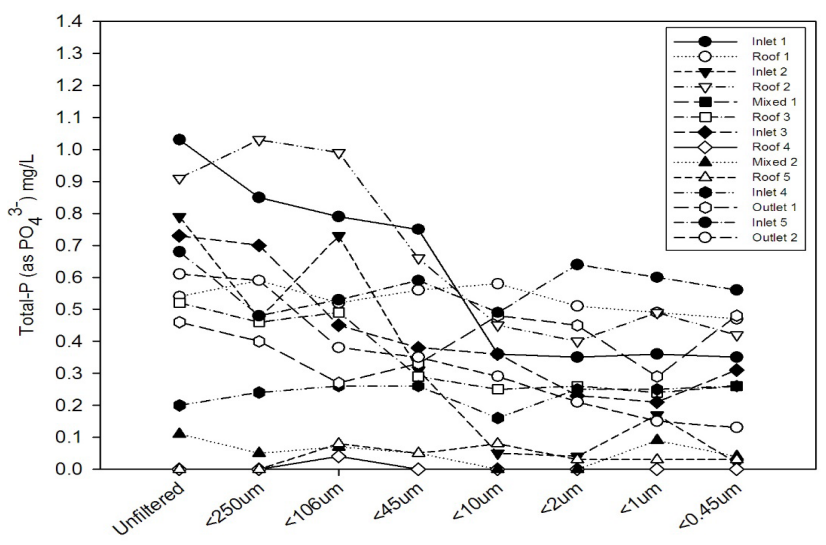

Figure 3 Total phosphorus by particle size for all samples (Morquecho 2005).

Figure 4 shows the total phosphorus pollutant strengths for different particle size ranges for Morquecho's (2005) residential and commercial area samples. As shown, the smaller particles have somewhat elevated concentrations (due to large surface areas per mass with pollutant sorption onto surfaces). Large particles have the greatest pollutant strengths for nutrients as they are predominately comprised of large organic material. At some industrial sites, larger particles may be of metallic material instead of soil or organic material, with a less distinct nutrient increase with the large particle sizes.

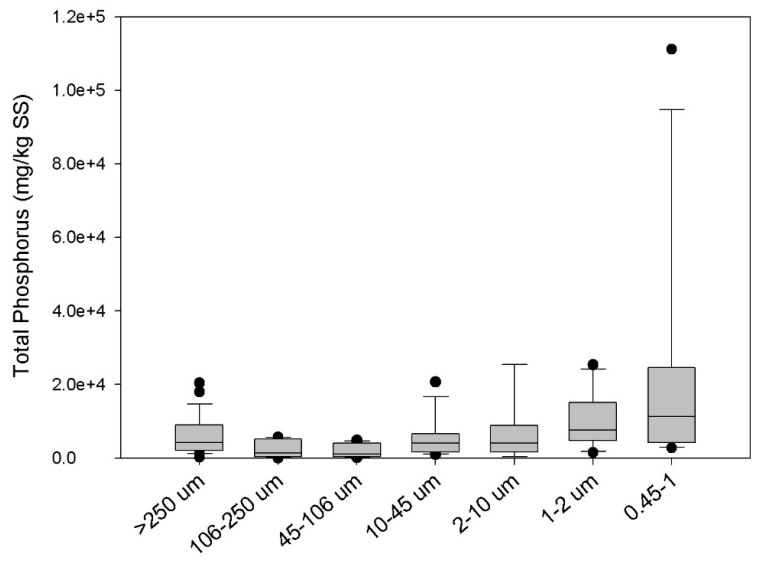

Figure 4 Total phosphorus strength by particle size, all samples combined (Morquecho 2005).

Figure 5 shows the accumulative contributions of different particle size ranges, while Figure 6 shows the particulate strengths for parking lot stormwater samples collected by Cai (2015). The largest size range has the largest strengths compared to other particle sizes, likely due to the organic content of this size range. Control down to $\sim 10 \mu \mathrm{m}$ would remove almost all of the particulate phosphorus. The filterable phosphorus concentrations are as high as $100 \mu \mathrm{g} / \mathrm{L}$, requiring additional treatment targeting 
these filterable forms to reduce the phosphorus levels to typically acceptable levels.

Figures 7 and 8 show similar data for total nitrogen, also obtained by Cai (2015) at a parking lot site. Again, the large particles have high total nitrogen, likely due to their large organic content. However, as for total phosphorus, removal of particles down to $\sim 10 \mu \mathrm{m}$ is needed for high nitrogen removals, although there is more variability for nitrogen.

Figures 9 and 10 are plots showing the chemical oxygen demand (COD) particulate strengths for different particle sizes for source residential and commercial area sheetflow samples evaluated by Morquecho (2005). The fines have substantially larger COD values compared to the larger particles, but their range of concentrations for the small size is large. On average, the unfiltered roof runoff samples had a lower concentration of COD compared to the inlet samples.

Cai (2015) examined COD particulate strengths for parking lot samples, as shown in Figures 11 and 12. As for the other samples, larger particles had greater COD particulate strengths. Removal of all particulates down to $\sim 10 \mu \mathrm{m}$ or $20 \mu \mathrm{m}$ would remove almost all of the particulate bound COD. The filterable COD may still be substantial, indicating large amounts of dissolved organic material.

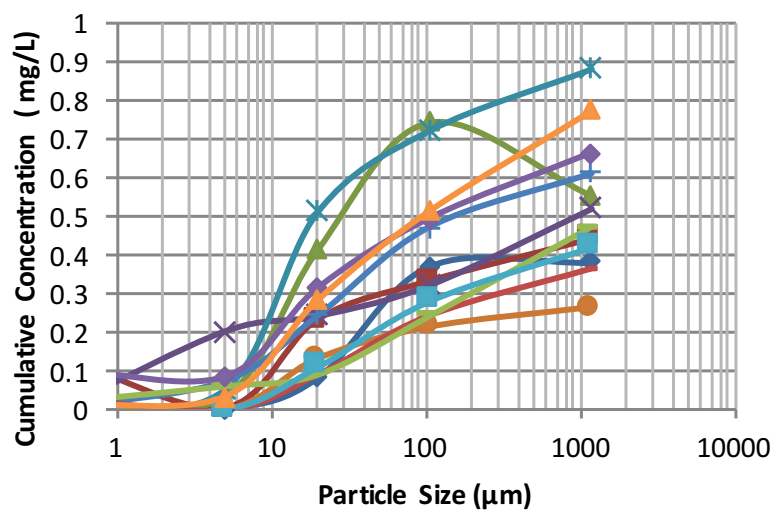

Figure 5 Cumulative concentration of total phosphorous by particle size (Cai 2015).

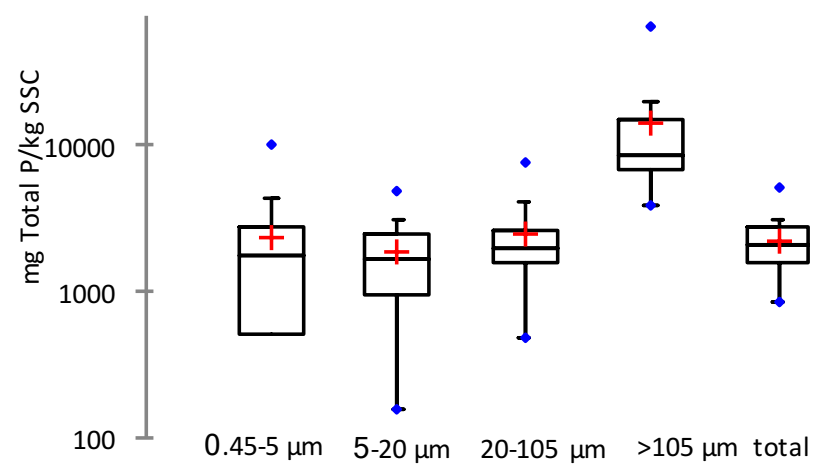

Particle Size Range

Figure 6 Total phosphorous particulate strengths by particle size (Cai 2015).

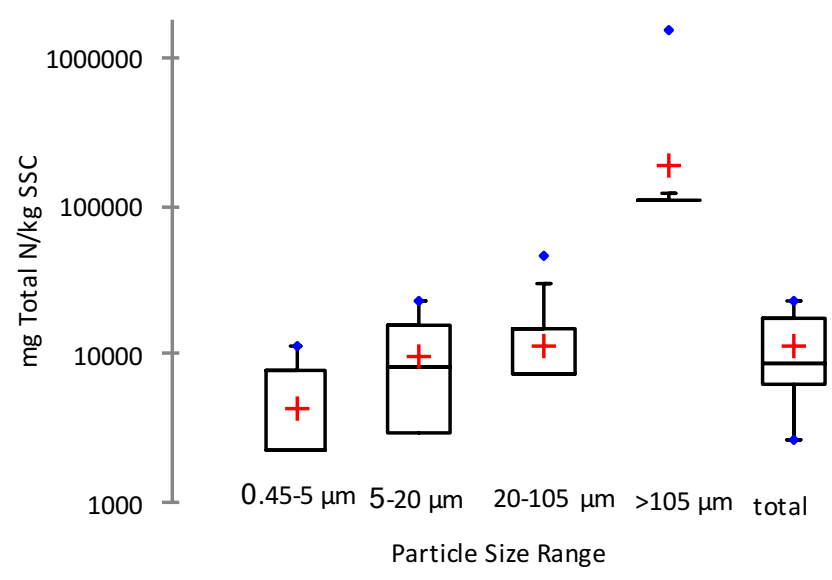

Figure 7 Total nitrogen particulate strengths by particle size (Cai 2015).

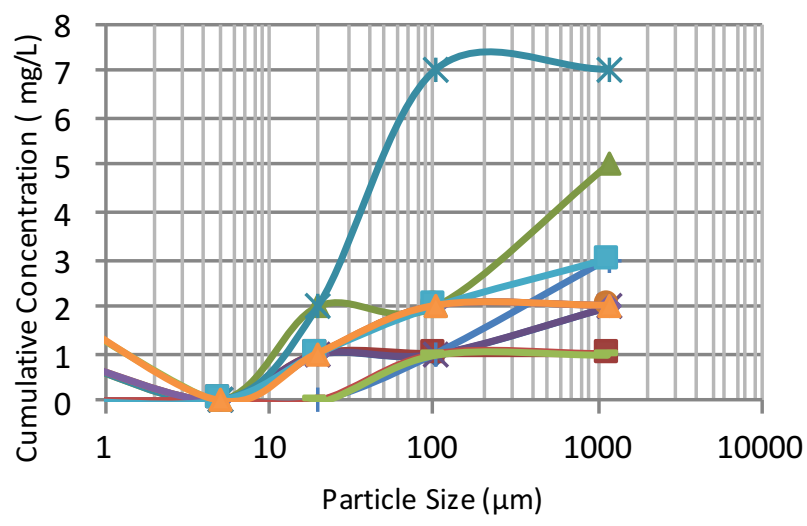

Figure 8 Cumulative concentration of total nitrogen by particle size (Cai 2015).

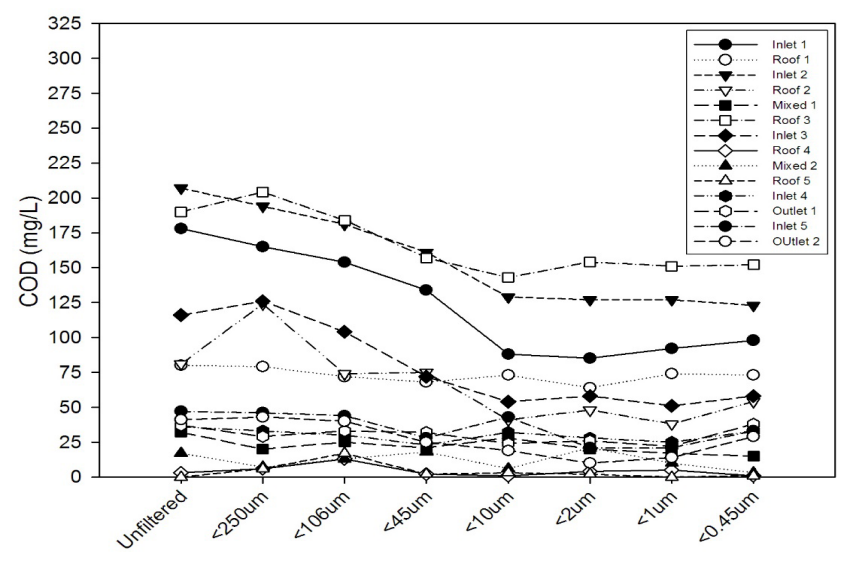

Figure 9 Chemical oxygen demand by particle size for all samples (Morquecho 2005). 


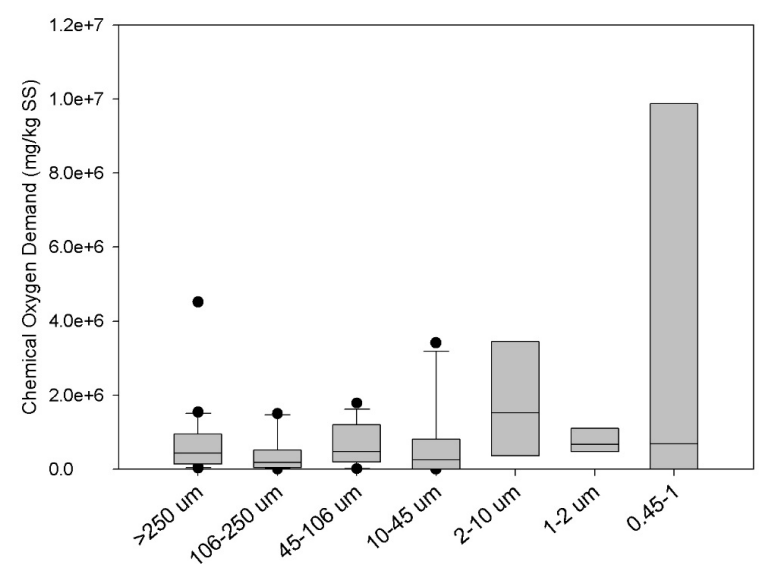

Figure 10 Chemical oxygen demand loading by particle size, all residential and commercial area samples combined (Morquecho 2005).

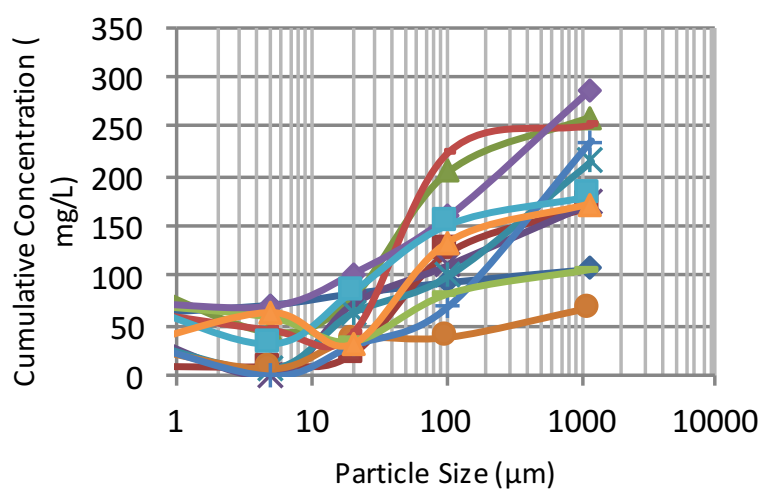

Figure 11 Cumulative concentration of COD by particle size (Cai 2015).

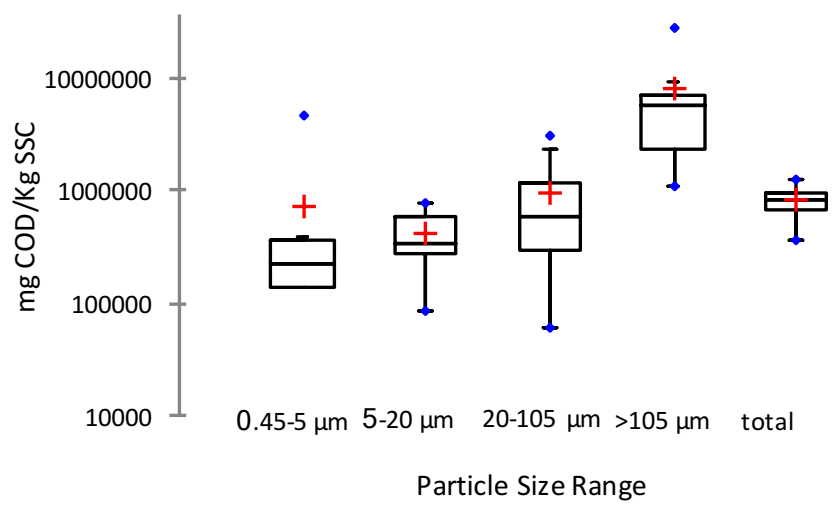

Figure 12 COD particulate strengths by particle size (Cai 2015).

\subsection{Heavy Metals}

Several stormwater monitoring projects over the years have examined heavy metal pollutant strengths associated with different sized stormwater particulates.

Indirect indications of pollutant strengths by particle size are available from stormwater control monitoring projects. Examinations of sedimentation based controls can directly relate to particle settling characteristics, for example. Randall et al. (1982) recognized the strong correlation between pollutant removal effectiveness in wet detention ponds and pollutant associations with suspended solids. High lead removals were related to lead's affinity for suspended solids, while much smaller removals of $\mathrm{BOD}_{5}(5 \mathrm{~d}$ biochemical oxygen demand) and phosphorus were usually obtained because of their significant filterable fractions.

Dally et al. (1983) monitored heavy metal forms in runoff entering and leaving a wet detention pond serving a bus maintenance area. They found that metals entering the monitored pond were generally in particulate $(>0.2 \mu \mathrm{m})$ forms and the effluent was mostly in filterable $(<0.2 \mu \mathrm{m})$ forms. The observed total metal removals by the pond were generally favourable, but the filterable metal outflows were much greater than the filterable metal inflows, an indication of biological or chemical transformations. This effect was most pronounced for cadmium and lead. Very little changes in zinc were found, probably because most of the zinc entering the pond was already in filterable forms. These metal transformations may be more pronounced in wet detention ponds than in natural waters because of potentially more favourable (for metal dissolution) $\mathrm{pH}$ and ORP (oxidation-reduction potential) conditions in wet pond sediments. Other studies have found similar transformations in the forms and availability of nutrients in wet detention ponds, usually depending on the extent of algal growth and algal removal operations.

The pollutant strengths of stormwater particulates were calculated for each pollutant and plotted on a probability chart for the Monroe St. (Madison, Wisconsin) pond data from House et al. (1993). An example is shown in Figure 13 for zinc. All pollutants had higher outlet than inlet particulate pollutant strength values due to preferential removal of large particles in the detention pond, leaving relatively more small particles in the discharge water, further indicating that the small particles in stormwater have higher pollutant strengths than the large particles. 


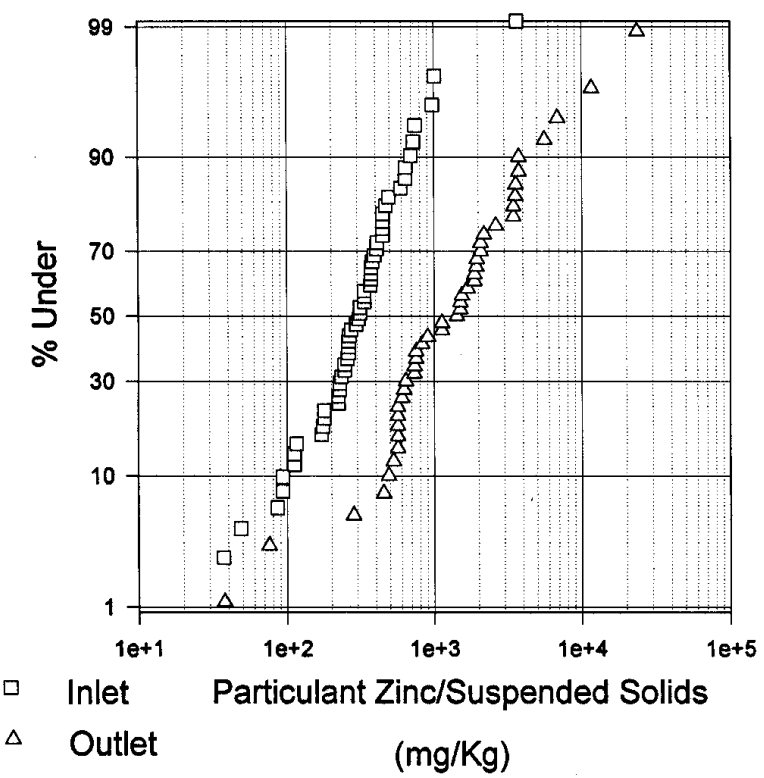

Figure 13 Particulate pollutant strengths for zinc (data from House et al. 1993).

Projects have also separated stormwater particulates by size range and chemically analyzed each range separately. Vignoles and Herremans (1995) examined heavy metal associations with different particles sizes in stormwater samples from Toulouse, France. They found that the majority of the heavy metal loadings in stormwater were associated with particles $<10 \mu \mathrm{m}$ in size, as shown in Table 2.

Table 2 Percentages of suspended solids and distribution of heavy metal loadings associated with various stormwater particulate sizes in Toulouse, France (percentage associated with size class, concentration in $\mathrm{mg} / \mathrm{kg})$.

\begin{tabular}{lccccccc}
\hline & $>100 \mu \mathrm{m}$ & $50 \mu \mathrm{m}-$ & $40 \mu \mathrm{m}-$ & $32 \mu \mathrm{m}-$ & $20 \mu \mathrm{m}-$ & $10 \mu \mathrm{m}-$ & \multirow{2}{*}{$100 \mu \mathrm{m}$} \\
& & $50 \mu \mathrm{m}$ & $40 \mu \mathrm{m}$ & $32 \mu \mathrm{m}$ & $20 \mu \mathrm{m}$ & $<$ \\
\hline Suspended solids & $15 \%$ & $11 \%$ & $6 \%$ & $9 \%$ & $10 \%$ & $14 \%$ & $35 \%$ \\
Cadmium & $18(13)$ & $11(11)$ & $6(11)$ & $5(6)$ & $5(5)$ & $9(6)$ & $46(14)$ \\
Cobalt & $9(18)$ & $5(16)$ & $4(25)$ & $6(20)$ & $6(18)$ & $10(22)$ & $60(53)$ \\
Chromium & $5(21)$ & $4(25)$ & $2(26)$ & $6(50)$ & $3(23)$ & $9(39)$ & $71(134)$ \\
Copper & $7(42)$ & $8(62)$ & $3(57)$ & $4(46)$ & $4(42)$ & $11(81)$ & $63(171)$ \\
Manganese & $8(86)$ & $4(59)$ & $3(70)$ & $3(53)$ & $4(54)$ & $7(85)$ & $71(320)$ \\
Nickel & $8(31)$ & $5(27)$ & $4(31)$ & $5(31)$ & $5(27)$ & $10(39)$ & $63(99)$ \\
Lead & $4(104)$ & $4(129)$ & $2(181)$ & $4(163)$ & $5(158)$ & $8(247)$ & $73(822)$ \\
Zinc & $5(272)$ & $6(419)$ & $3(469)$ & $5(398)$ & $5(331)$ & $16(801)$ & $60(1232)$ \\
\hline
\end{tabular}

Source: Vignoles and Herremans (1995)

Morquecho (2005) collected Tuscaloosa, Alabama urban area sheetflow and outfall samples for analyses of discrete particle size ranges. Table 3 lists the percentage reduction in pollutants after removing larger particles than shown. These are for residential and commercial sheetflow and outfall samples and indicate a smaller particulate bound portion of these contaminants than for some of the other land use samples. Total solids and turbidity were reduced $>50 \%$ by removal of all particulates $>0.45 \mu \mathrm{m}$. The other pollutants, especially the heavy metals, were reduced much less, even after filtration down to $0.45 \mu \mathrm{m}$. Previously, other Tuscaloosa, Alabama projects found much more zinc, lead and total phosphorus were reduced by reduction in particle size (Johnson et al. 2003).

Table 3 Average percent reduction in pollutants after controlling for particle size indicated (Morquecho 2005).

\begin{tabular}{lccccc}
\hline & $250 \mu \mathrm{m}$ & $45 \mu \mathrm{m}$ & $10 \mu \mathrm{m}$ & $2 \mu \mathrm{m}$ & $0.45 \mu \mathrm{m}$ \\
\hline Total solids & $6 \%$ & $31 \%$ & $43 \%$ & $44 \%$ & $42 \%$ \\
Suspended solids & 23 & 64 & 88 & 93 & 100 \\
Turbidity & 30 & 42 & 65 & 69 & 83 \\
COD & 10 & 23 & 34 & 32 & 33 \\
Total phosphorus & 13 & 25 & 38 & 38 & 37 \\
Zinc & 5 & 14 & 20 & 26 & 22 \\
Copper & 6 & 14 & 25 & 27 & 38 \\
Cadmium & 5 & 10 & 9 & 14 & 15 \\
Lead & 6 & 16 & 22 & 35 & 30 \\
\hline
\end{tabular}

These heavy metal filterable fractions were much greater compared to those seen at the inlet to the Monroe Street wet detention pond (House et al. 1993), also serving a residential and commercial area in Madison, Wisconsin. In the Wisconsin study, $87 \%$ copper, $96 \%$ lead and $66 \%$ zinc were associated with the particulate fraction.

Tables 4 through 6 below summarize the pollutant strengths for each size range for inlet, roof, and storm drain outlet samples, respectively (Morquecho 2005). The normal trend is an increase in pollutant strengths with a decrease in particle size. For the inlet samples, most values tend to increase with a decrease in particle size. There is some variability, but the highest values are seen for the smaller $(<10 \mu \mathrm{m})$ particle sizes. The same general trend is seen for the roof runoff and storm drain outlet samples.

Typical soil values for copper, lead and zinc are generally around $100 \mathrm{mg} / \mathrm{kg}$ (Lindsay 1979). The values reported by Morquecho (2005) are much higher, especially for the roof runoff samples. The roof runoff samples included at least two samples from a coated aluminum roof (Tuscaloosa courthouse). Heavy metals can also be influenced by the drainage gutters and downspouts. In comparison, these values are higher than those seen by Pitt and McLean (1986) in Toronto where they found copper values of $\sim 30 \mathrm{mg} / \mathrm{kg}$ to $200 \mathrm{mg} / \mathrm{kg}$ in most residential and commercial areas (particulates $<125 \mu \mathrm{m}$ ), and from $100 \mathrm{mg} / \mathrm{kg}$ to $>1000 \mathrm{mg} / \mathrm{kg}$ at industrial sites. Lead values for these samples were surprisingly high given the decreased use of leaded gasoline. Vignoles and Herremans (1995) found lead particulate strength values of $\sim 800 \mathrm{mg} / \mathrm{kg}$ for particulates $<10 \mu \mathrm{m}$. Previous work in the late 1970s found values of lead of $\sim 3500 \mathrm{mg} / \mathrm{kg}$ for street dirt samples (Pitt 1979). Storm drain outlet particulate strength values of lead and cadmium were higher than inlets, but zinc and copper values were similar, indicating the capture of 
Table 4 Summary table showing average pollutant associations for different particle sizes for combined (2001 and 2004/2005) inlet samples; $\mathrm{N}=13$, rounded to two significant figures (Morquecho 2005).

\begin{tabular}{|c|c|c|c|c|c|c|c|c|c|c|c|c|}
\hline & \multicolumn{2}{|c|}{ Total phosphorus } & \multicolumn{2}{|c|}{$C O D$} & \multicolumn{2}{|c|}{ Zinc } & \multicolumn{2}{|c|}{ Copper } & \multicolumn{2}{|c|}{ Lead } & \multicolumn{2}{|c|}{ Cadmium } \\
\hline & $\mathrm{mg} / \mathrm{kg} \mathrm{SS}$ & $\mathrm{COV}$ & $\mathrm{mg} / \mathrm{kg} \mathrm{SS}$ & $\mathrm{COV}$ & $\mathrm{mg} / \mathrm{kg} \mathrm{SS}$ & $\mathrm{COV}$ & $\mathrm{mg} / \mathrm{kgSS}$ & $\mathrm{COV}$ & $\mathrm{mg} / \mathrm{kg} \mathrm{SS}$ & $\mathrm{COV}$ & $\mathrm{mg} / \mathrm{kgSS}$ & $\mathrm{COV}$ \\
\hline$>250 \mu \mathrm{m}$ & 8400 & 1.28 & 640000 & 0.91 & 2300000 & 1.83 & 180000 & 1.80 & 270000 & 1.16 & 24000 & 1.24 \\
\hline $106 \mu \mathrm{m}-250 \mu \mathrm{m}$ & 2400 & 0.95 & 140000 & 0.99 & 680000 & 1.30 & 180000 & 1.47 & 38000 & 1.03 & 22000 & 1.29 \\
\hline $45 \mu \mathrm{m}-106 \mu \mathrm{m}$ & 1900 & 1.34 & 720000 & 0.85 & 2000000 & 1.28 & 220000 & 1.04 & 130000 & 1.30 & 14000 & 0.93 \\
\hline $10 \mu \mathrm{m}-45 \mu \mathrm{m}$ & 4400 & 0.69 & 1100000 & 1.73 & 2600000 & 1.01 & 270000 & 0.51 & 400000 & 1.60 & 140000 & na \\
\hline $2 \mu \mathrm{m}-10 \mu \mathrm{m}$ & 150000 & 0.54 & 2500000 & 0.51 & 1700000 & 1.35 & 220000 & 0.67 & 1000000 & 1.25 & 150000 & 0.54 \\
\hline
\end{tabular}

Note: $n a=$ too few detectable observations for calculation.

Table 5 Summary table showing average pollutant associations for different particle sizes for roof runoff samples; $\mathrm{N}=5$, rounded to two significant figures (Morquecho 2005).

\begin{tabular}{|c|c|c|c|c|c|c|c|c|c|c|c|c|}
\hline & \multicolumn{2}{|c|}{ Total phosphorus } & \multicolumn{2}{|c|}{ COD } & \multicolumn{2}{|c|}{ Zinc } & \multicolumn{2}{|c|}{ Copper } & \multicolumn{2}{|c|}{ Lead } & \multicolumn{2}{|c|}{ Cadmium } \\
\hline & $\mathrm{mg} / \mathrm{kg} \mathrm{SS}$ & $\mathrm{COV}$ & $\mathrm{mg} / \mathrm{kg} \mathrm{SS}$ & $\mathrm{COV}$ & $\mathrm{mg} / \mathrm{kg} \mathrm{SS}$ & $\mathrm{COV}$ & $\mathrm{mg} / \mathrm{kgSS}$ & $\mathrm{COV}$ & $\mathrm{mg} / \mathrm{kgSS}$ & $\mathrm{COV}$ & $\mathrm{mg} / \mathrm{kg} \mathrm{SS}$ & $\mathrm{COV}$ \\
\hline$>250 \mu \mathrm{m}$ & 4400 & 0.77 & 300000 & 0.91 & 2800000 & 1.15 & 150000 & 0.28 & 630000 & 0.35 & 13000 & 1.24 \\
\hline $106 \mu \mathrm{m}-250 \mu \mathrm{m}$ & 1400 & na & 510000 & 0.95 & 580000 & 1.38 & 6200 & na & 53000 & 0.83 & 1900 & na \\
\hline $10 \mu \mathrm{m}-45 \mu \mathrm{m}$ & 3000 & 0.56 & 840 & 1.18 & 5589000 & 1.41 & 310000 & na & 150000 & 1.40 & 4600 & na \\
\hline $2 \mu \mathrm{m}-10 \mu \mathrm{m}$ & na & na & 370000 & na & 2000000 & 0.40 & na & na & 120000 & na & 5400 & 1.03 \\
\hline
\end{tabular}

Note: $\mathrm{na}=$ too few detectable observations for calculation.

Table 6 Summary table showing average pollutant associations for different particle sizes for storm drain outlet samples; N=10, rounded to two significant figures (Morquecho 2005).

\begin{tabular}{|c|c|c|c|c|c|c|c|c|c|c|c|c|}
\hline & \multicolumn{2}{|c|}{ Total phosphorus } & \multicolumn{2}{|c|}{ COD } & \multicolumn{2}{|c|}{ Zinc } & \multicolumn{2}{|c|}{ Copper } & \multicolumn{2}{|c|}{ Lead } & \multicolumn{2}{|c|}{ Cadmium } \\
\hline & $\mathrm{mg} / \mathrm{kg} \mathrm{SS}$ & $\mathrm{COV}$ & $\mathrm{mg} / \mathrm{kgSS}$ & $\mathrm{COV}$ & $\mathrm{mg} / \mathrm{kg} \mathrm{SS}$ & $\mathrm{COV}$ & $\mathrm{mg} / \mathrm{kg} \mathrm{SS}$ & $\mathrm{COV}$ & $\mathrm{mg} / \mathrm{kg} \mathrm{SS}$ & $\mathrm{COV}$ & $\mathrm{mg} / \mathrm{kg} \mathrm{SS}$ & $\mathrm{COV}$ \\
\hline$>250 \mu \mathrm{m}$ & 5900 & 1.00 & 1100000 & 1.49 & 800000 & 0.55 & 120000 & 0.55 & 140000 & 0.57 & 9400 & 0.35 \\
\hline $106 \mu \mathrm{m}-250 \mu \mathrm{m}$ & 1900 & 1.45 & 780000 & 1.33 & 52000 & 0.68 & 20000 & 0.52 & 30000 & 0.54 & 8300 & 1.29 \\
\hline $10 \mu \mathrm{m}-45 \mu \mathrm{m}$ & 3400 & 0.73 & 720000 & 0.49 & 990000 & na & 130000 & 1.06 & 150000 & 1.22 & 9100 & 0.67 \\
\hline $2 \mu \mathrm{m}-10 \mu \mathrm{m}$ & 2800 & 0.69 & 340000 & na & 1700000 & 0.71 & 150000 & 0.69 & 75000 & 1.10 & 500000 & 1.41 \\
\hline
\end{tabular}

Note: $\mathrm{na}=$ too few detectable observations for calculation.

large particulates in the drainage system before discharge. These results further emphasize the need for stormwater control practices to capture very small particles.

Figures 14 through 17 below show the cumulative concentrations of pollutants for different particle size ranges, as reported by Cai (2015) for a parking lot site in Tuscaloosa, Alabama. The overall total concentrations would decrease with the preferential removal of large particulate. Small portions of the contaminants are found in the smallest particles, of sizes $<5 \mu \mathrm{m}$. The majority of the pollutant concentrations (and mass) are associated with the
$10 \mu \mathrm{m}$ to $100 \mu \mathrm{m}$ particle size range. Pre-treatment sedimentation controls removing only the largest particles (>100 $\mu \mathrm{m}$ for example) would only result in small reductions of the resulting effluent water concentrations (about 20\% removal). More effective treatment controls that can remove smaller particles would result in much better effluent quality (down to $\sim 5 \mu \mathrm{m}$, beyond which little additional benefit is likely by sedimentation processes for these data).

Cai (2015) also calculated the pollutant strengths for the different particle size ranges for metals in the parking area runoff, as shown in Figures 18 through 23 below. 


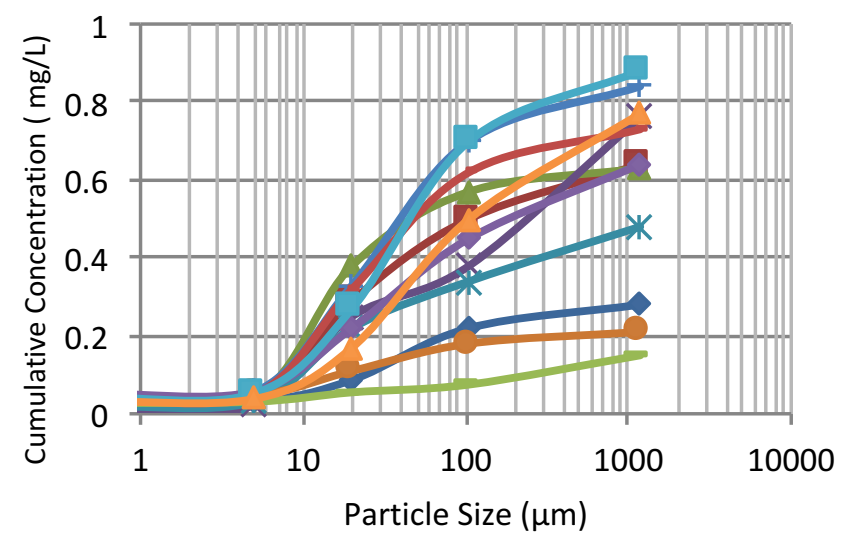

Figure 14 Cumulative concentration of total copper by particle size (Cai 2015).

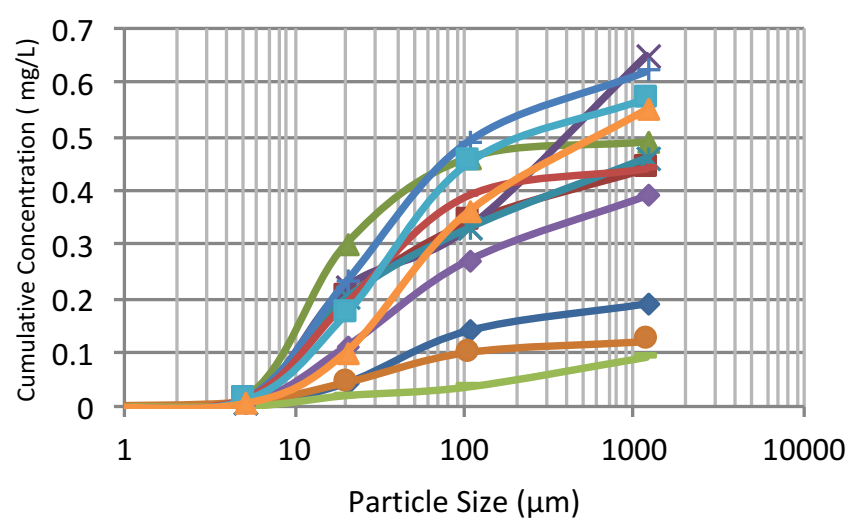

Figure 15 Cumulative concentration of total lead by particle size (Cai 2015).

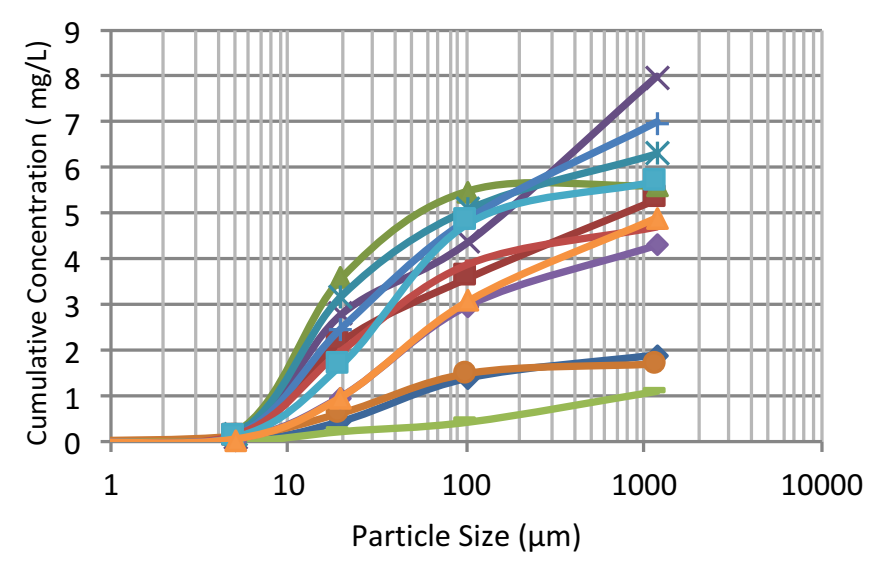

Figure 16 Cumulative concentration of total aluminum by particle size (Cai 2015).

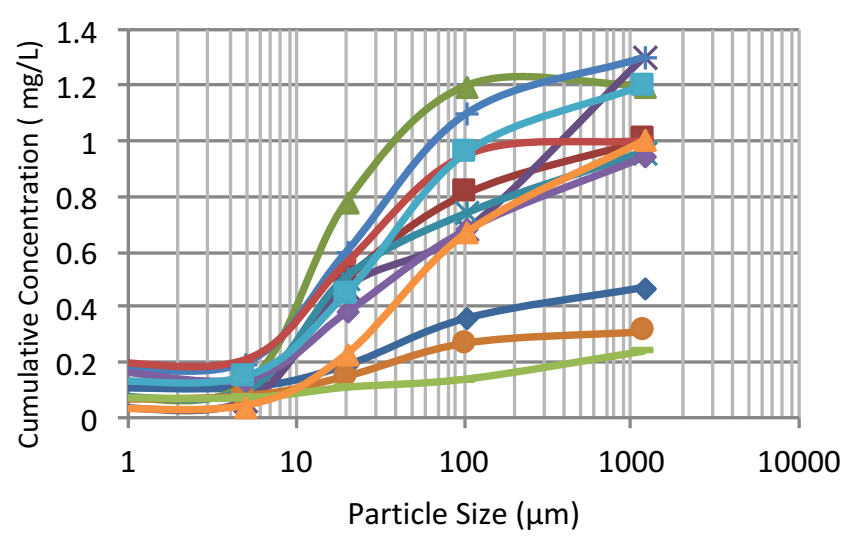

Figure 17 Cumulative concentration of total zinc by particle size (Cai 2015).

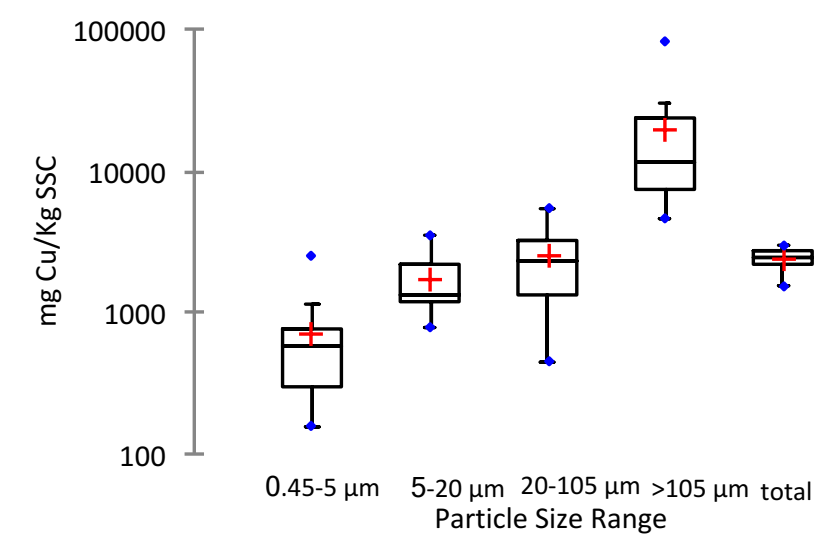

Figure 18 Copper particulate strengths by particle size (Cai 2015).

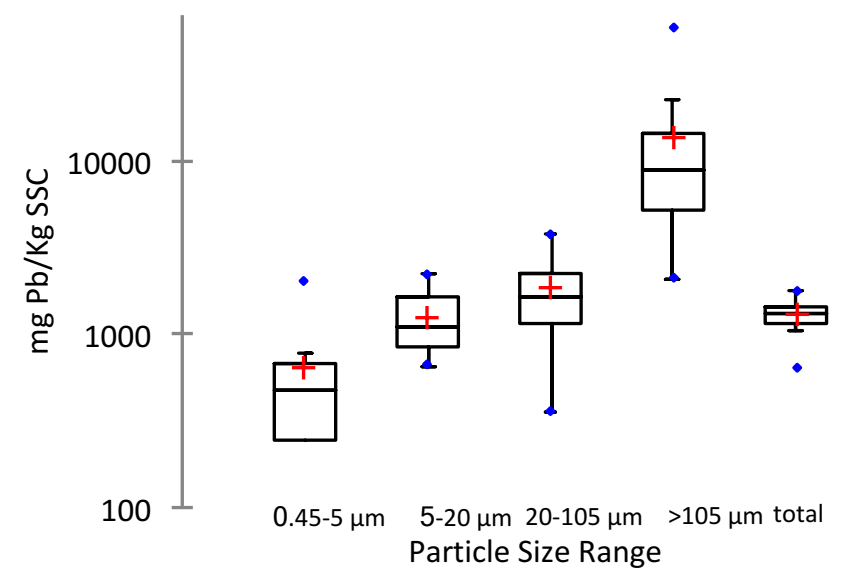

Figure 19 Lead particulate strengths by particle size (Cai 2015). 


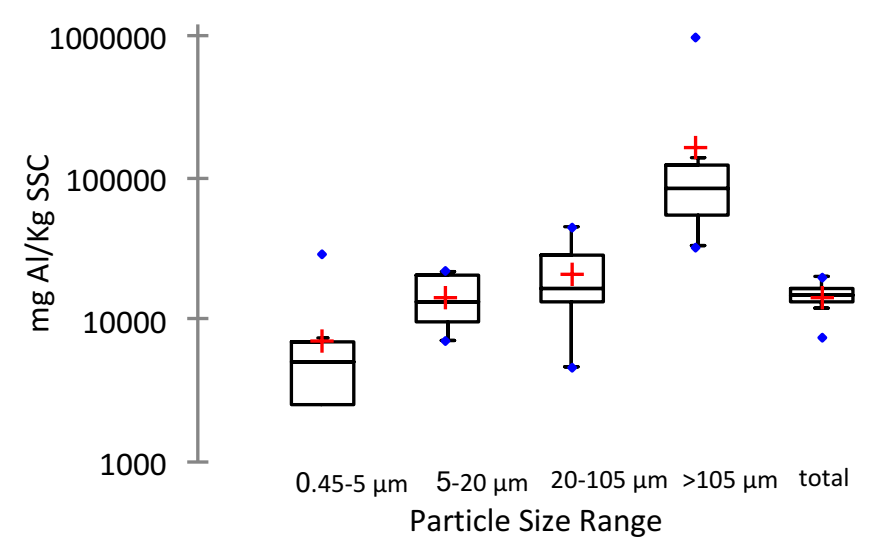

Figure 20 Aluminum particulate strengths by particle size

(Cai 2015).

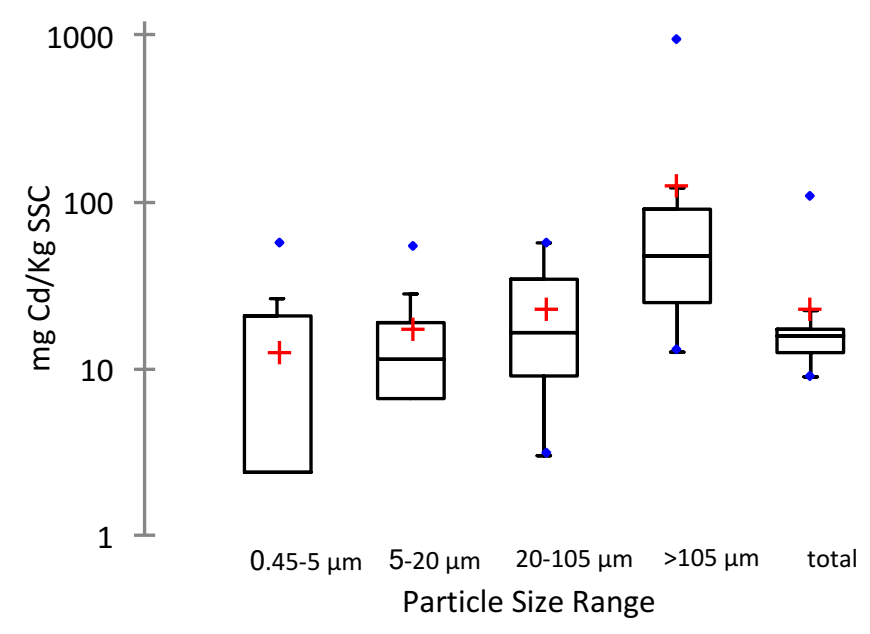

Figure 21 Cadmium particulate strengths by particle size

(Cai 2015).

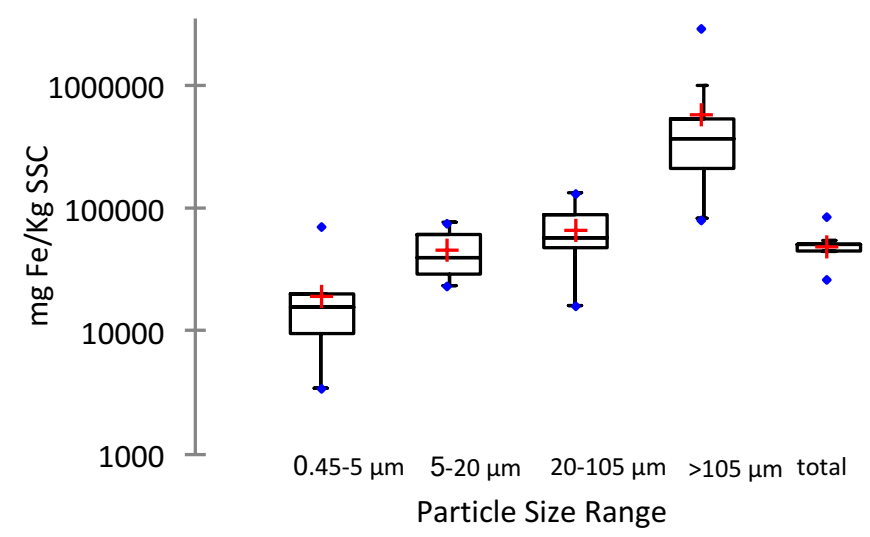

Figure 22 Iron particulate strengths by particle size (Cai

2015).

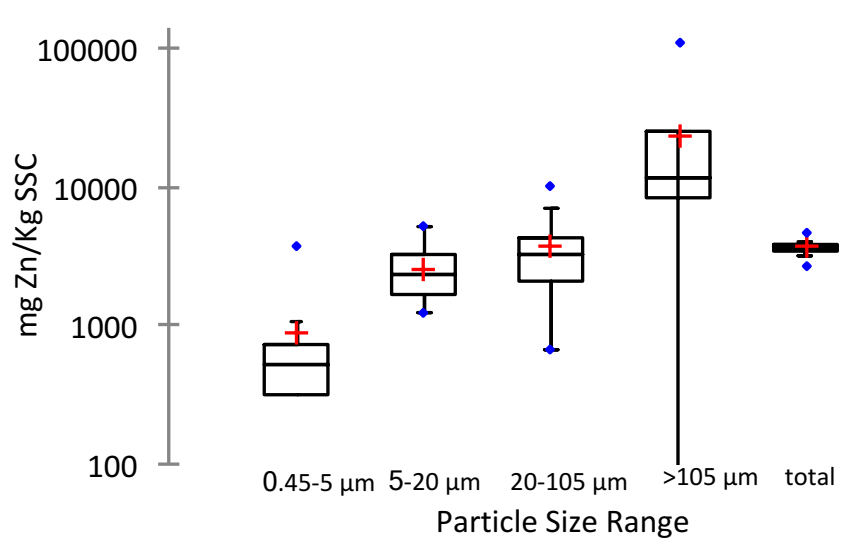

Figure 23 Zinc particulate strengths by particle size (Cai 2015).

At this parking area site (mostly asphalt, with landscaping and roof runoff contributions), the particulate strengths tended to increase as the particle sizes increase. These results were similar to the results observed by Sansalone and Buchberger (1997a; 1997b). In general, metals tend to preferentially adsorb to smaller particle sizes due to larger surface areas. In this specific case, the higher particulate strengths associated with larger particle size ranges may be related to the nature of the runoff particulates from the site due to large organic material from the adjacent landscaped areas.

\subsection{Polycyclic Aromatic Hydrocarbons}

Bathi (2008) investigated Tuscaloosa, Alabama urban area stream sediment polycyclic aromatic hydrocarbon (PAH) values for different size ranges. PAHs can occur in soluble and particulate associated forms; however, previous studies have shown that particulate associated PAHs are most abundant in stormwater (Pitt et al. 1999; Mahler et al. 2005; Hwang and Foster 2006). Bathi also conducted fugacity based modeling to calculate the phase portioning of individual PAHs in an aquatic environment under equilibrium conditions for comparison to observed field values. The model results showed similar trends as observed with large associations of PAHs with sediments compared to the liquid or air portions, especially for high molecular weight PAHs.

Variations in organic content of the particulate matter in the water has been reported to affect the particulate $\mathrm{PAH}$ associations (Zhou et al. 1998). Recent investigations have also found high PAH concentrations associated with large organic material trapped in stormwater floatable control devices (Rushton 2006). The composition of the sediment (organic matter and other litter, vs inert material) affects the association of PAHs with the sediment.

Sediment samples were collected from three different creeks in and around Tuscaloosa and Northport, Alabama (Cribb's Mill Creek, Carroll's Creek and Hunter (reek). All the samples were collected in pre-cleaned and autoclaved glass sample bottles 
using a manual dipper sampler made from polypropylene. The collected sediment samples were dried in aluminum trays at $104{ }^{\circ} \mathrm{C}$ to remove moisture and were then sieved using a mechanical shaker and a set of sieves. All of the chemical analyses were conducted on the material retained by the sieves having openings of $45 \mu \mathrm{m}, 90 \mu \mathrm{m}, 180 \mu \mathrm{m}, 355 \mu \mathrm{m}, 710 \mu \mathrm{m}, 1400 \mu \mathrm{m}$ and $2800 \mu \mathrm{m}$. In addition, the largest size fraction was separated into inert and organic fractions, with the large organic material (mostly leaves) manually separated for separate analyses. All the size fractionated sediment particles were analyzed for PAH concentrations using thermal desorption GC/MS (gas chromatography/ mass spectrometry).

The observed PAH concentrations for the different sediment particle sizes and associated standard deviations are shown in Table 7. Figures 24 through 29 below are box and whisker plots of PAH concentrations associated with the different sediment fractions. As expected, there were large variations in the measured PAH concentrations. The PAH concentrations were therefore tested for their normality for each site and size range using probability plots and Anderson-Darling statistical tests. Most of the PAH concentration groups were found to be normally distributed.

The PAH concentrations were found to be strongly associated with particulate matter. The variations in key characteristics of the sediment affect these associations. The fugacity level 1 partitioning calculations were performed for the PAHs in a hypothetical environmental system. This modeling approach indicated that except for the low molecular weight PAHs (naphthalene, fluorene, phenanthrene and anthracene), all the other studied PAHs were predominantly portioned with the sediment phase. The model predictions also indicated that the PAHs with Log $\mathrm{K}_{\text {ow }}$ (concentration in octanol/concentration in water) or Log $\mathrm{K}_{\mathrm{OC}}$ (soil organic carbon-water partitioning coefficient ) values $>\sim 4.5$ were mostly partitioned with the sediment phase, compared to other phases. The high molecular weight PAHs had a greater portion associated with the particulates than did the low molecular weight PAHs.

Bathi (2008) found that overall, all characteristics studied showed similar trends, with the smaller and larger particles found to have relatively higher values compared to the intermediate sized particles. Cluster analyses of the PAH concentrations for the different particle sizes showed that for most cases examined, the LOM (light organic matter) fraction was found to be a statistically separate sample category (having much higher concentrations) from all other sizes.

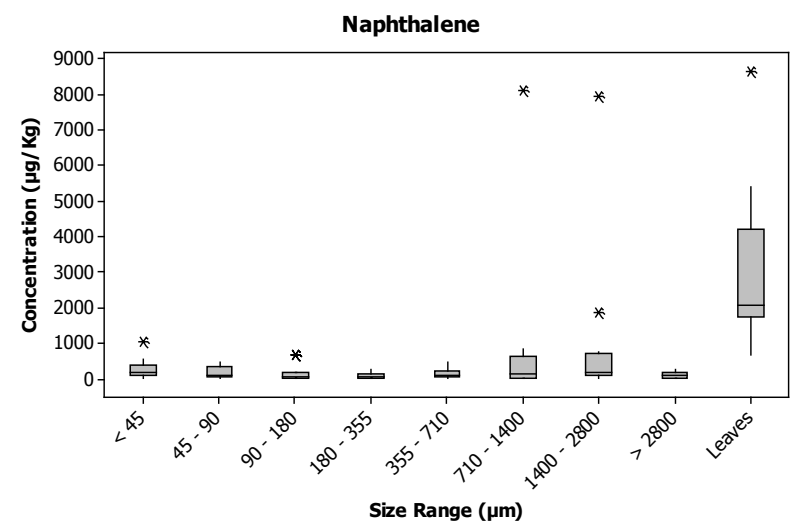

Figure 24 Size fractionation of naphthalene in urban creek sediments (Bathi 2008).

Table 7 Observed PAHs concentrations and associated standard deviations for urban creek sediment by size fractions (Bathi 2008).

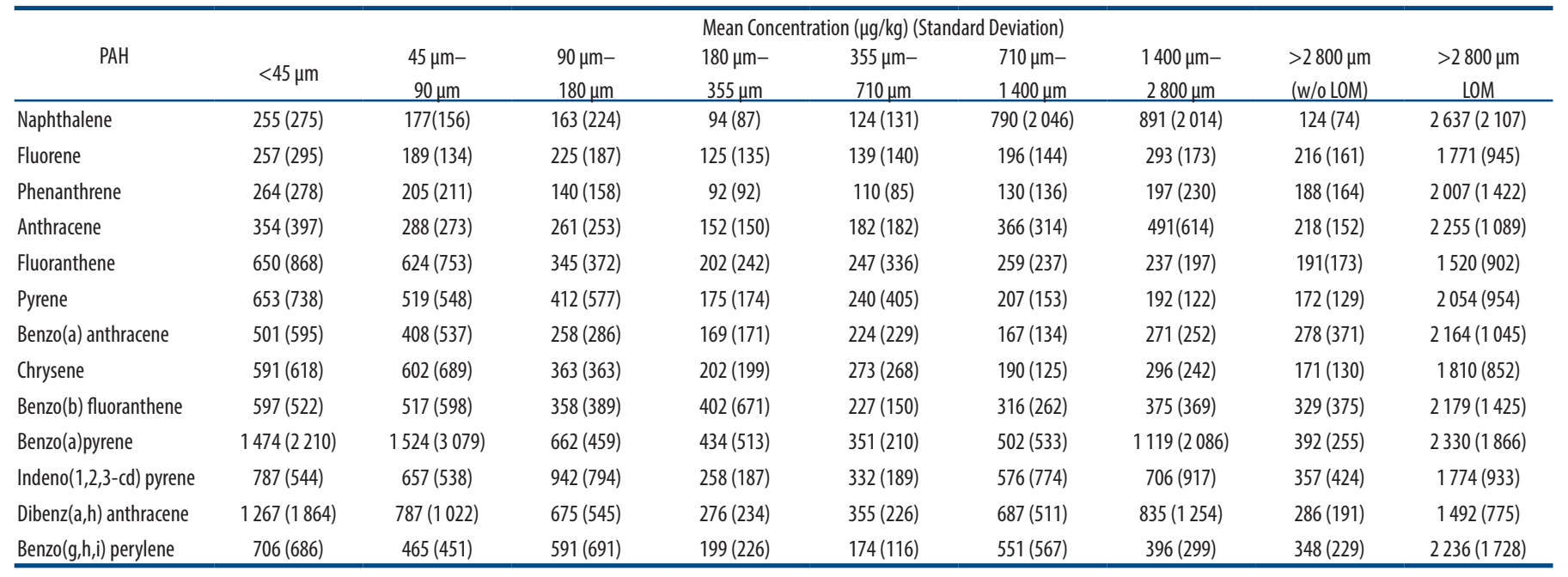




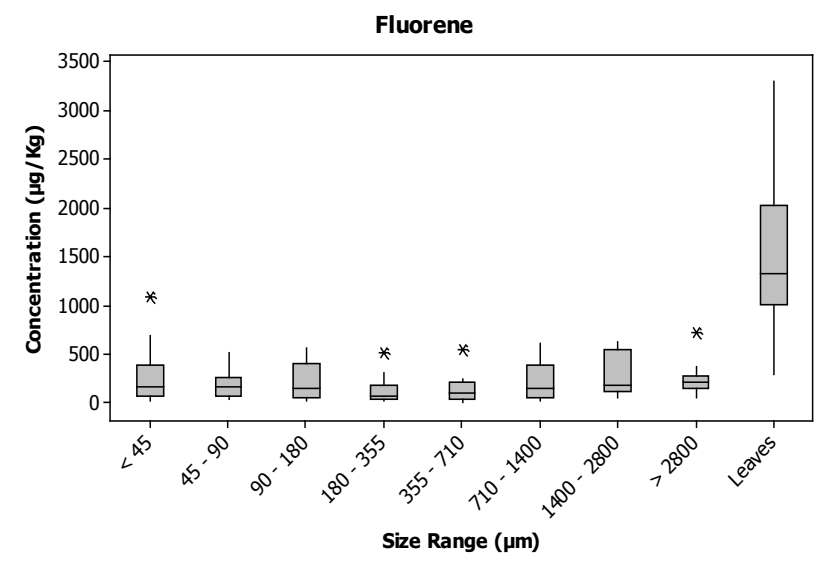

Figure 25 Size fractionation of fluorene in urban creek sediments (Bathi 2008).

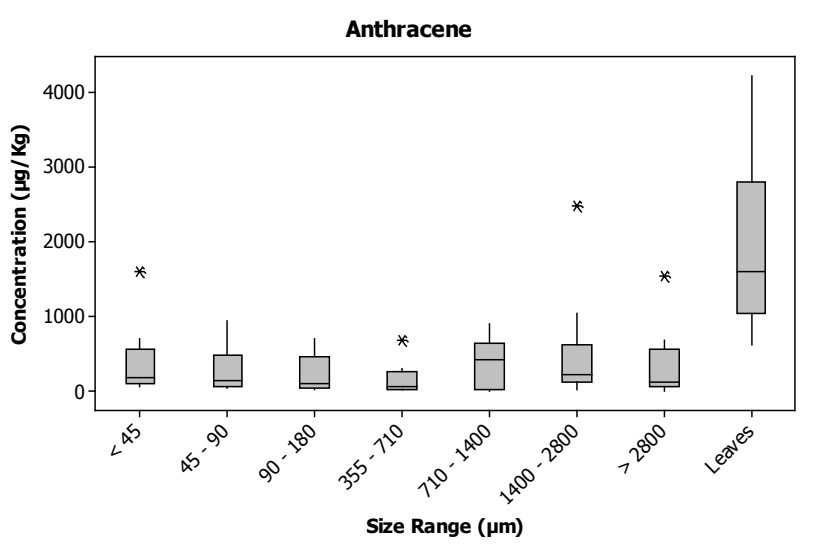

Figure 26 Size fractionation of anthracene in urban creek sediments (Bathi 2008).

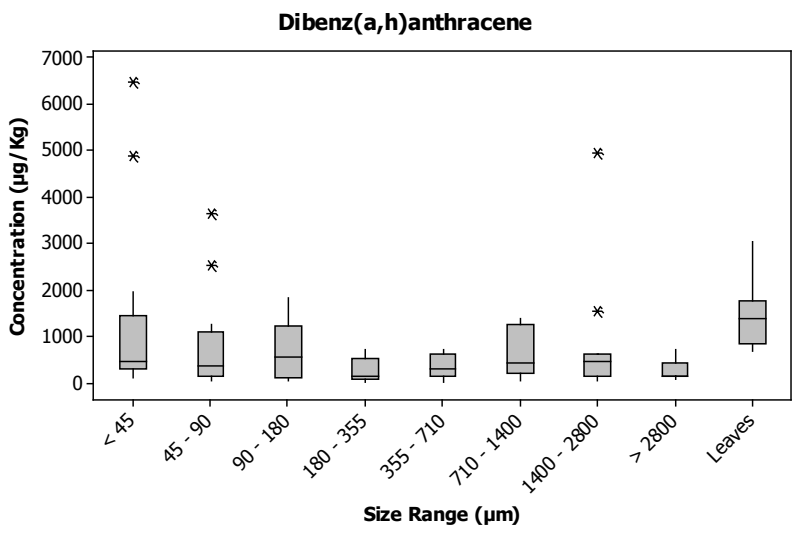

Figure 27 Size fractionation of $\operatorname{dibenz}(\mathrm{a}, \mathrm{h})$ anthracene in urban creek sediments (Bathi 2008).

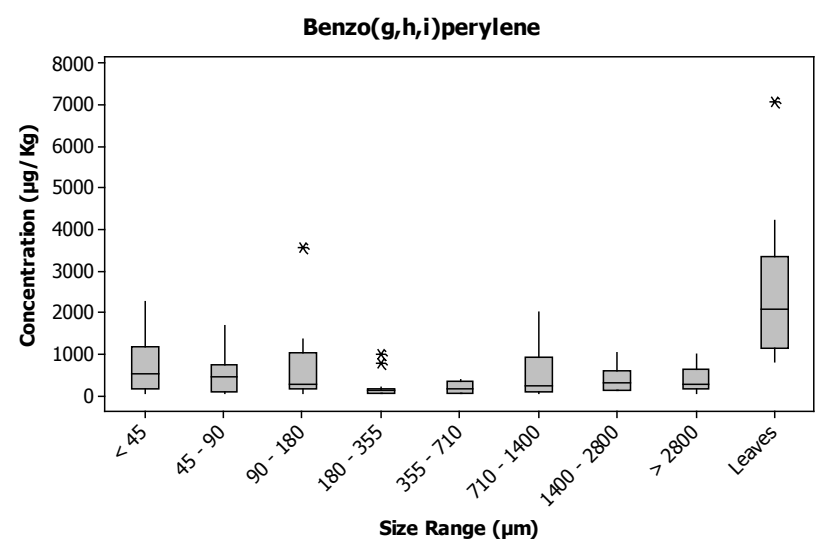

Figure 28 Size fractionation of benzo(g,h,i)perylene in urban creek sediments (Bathi 2008).

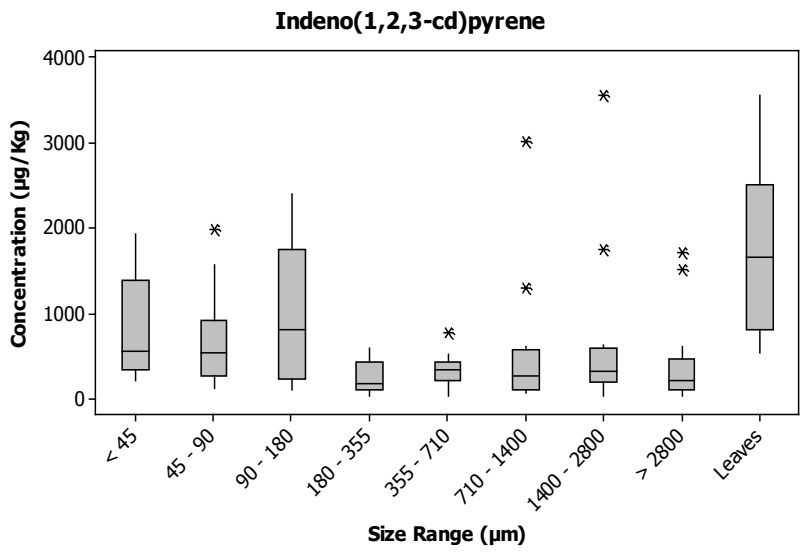

Figure 29 Size fractionation of indeno(1,2,3-cd)pyrene in urban creek sediments (Bathi 2008).

\section{Conclusions}

Several research efforts were reviewed and summarized in this paper concerning the particle associations of stormwater pollutants. Knowing the distribution of pollutants associated with different sized stormwater particles allows more accurate determinations of their sources, transport and control. Pollutants in stormwater runoff can to be separated into particulate-bound or filtered (filterable or dissolved) forms. Pollutant strengths are the contaminant concentrations associated with the particulate matter in the stormwater. The following are brief comments concerning these characteristics of stormwater particulates.

\subsection{Specific Gravity and Settling Rates}

In most cases, stormwater particulates have specific gravities in the range of 1.5 to 2.5 , depending on the mixture of organic and inert material in the particle. This corresponds to a relatively 
narrow range of settling rates for a specific particle size. Newton (laminar) and Stokes (turbulent) settling equations can be used to calculate reasonable settling rates for these particulates, as long as suitable characteristics are known. However, the specific gravities of the separate particle size ranges can vary by a larger amount. Specific gravity decreases as the organic content increases; larger particle sizes have lower specific gravity and greater organic material. With sedimentation treatment, preferential removal of higher specific gravity materials results in a shift to lower overall specific gravity of particulates in the effluent water for similar size classes. Scour of deposited sediment is dependent on the particle characteristics, including compaction of the material, compared to the shear stress (tractive force) of the flowing water.

\subsection{COD and Nutrients}

In residential and commercial areas, the smaller stormwater particles have the greatest concentrations of COD and nutrients (due to large surface areas per mass with pollutant sorption onto surfaces). Large particles have somewhat greater pollutant strengths for nutrients as they contain more organic material than other particle sizes. At industrial sites, larger particles may be of metallic material instead of soil and organic material, with less of an increase in nutrients for the larger particles.

At residential and commercial areas, removal of all particulates down to $\sim 10 \mu \mathrm{m}$ in the stormwater would remove almost all of the particulate associated phosphorus. However, the filterable phosphorus concentrations can still be high, requiring additional treatment targeting these filterable forms to reduce the phosphorus levels to typically acceptable levels.

\subsection{Heavy Metals}

Heavy metals are mostly associated with particulates in stormwater, except for zinc which can have large portions associated with the filterable fraction of the stormwater. Residential and commercial areas may have greater filterable fractions of metals in the stormwater than industrial sites which may have greater fractions associated with particulates. The normal trend is increases in pollutant strengths of metals with decreases in particle size. However, at industrial sites, large metallic portions may be associated with larger particles sizes due to the nature of the source material. The majority of the pollutant concentrations (and mass) were associated with the $10 \mu \mathrm{m}$ to $100 \mu \mathrm{m}$ particle size range.

Residential and commercial stormwater filterable heavy metals (zinc, cadmium and lead) are mostly bound to organic complexes or as colloids that are difficult to remove by ion exchange, but may be removed by sorption processes. Copper was mostly in ionic forms that can be readily removed by ion exchange (depending on the ionic strength).

Pre-treatment sedimentation controls removing only the largest particles (>100 $\mu \mathrm{m}$ for example) would only result in small reductions of the resulting effluent water concentrations. More effective treatment controls that can remove smaller particles would result in much better effluent quality (down to $\sim 5 \mu \mathrm{m}$, beyond which little additional benefit is likely by sedimentation processes).

\subsection{PAHs}

Because of their low volatility (low Henry's Law constant), high octonal-water partition coefficients $\left(\mathrm{K}_{\mathrm{ow}}\right)$ and high soil organic coefficients $\left(\mathrm{K}_{\mathrm{oc}}\right)$, many of the stormwater PAHs are preferentially adsorbed to particulate matter. The smaller and larger particles can have relatively higher PAH particulate strength values compared to the intermediate sized particles, depending on the organic content of the material. PAHs can be effectively controlled concurrent with high-levels of stormwater particulate control.

\subsection{Overview and New Research Directions}

Much information has been collected concerning stormwater quality over the years. However, most of these data are only for total constituent forms, with relatively little data differentiating filterable and particulate forms. The National Stormwater Quality Database (NSQD), as described in earlier papers in this journal (Maestre 2005; Maestre and Pitt 2006), contains both particulate and filterable forms of many stormwater constituents for up to 9000 events from throughout the United States (but with much fewer data for filterable forms than for total forms).

Modeling of constituent transport and control effectiveness, and especially the designs of stormwater controls, requires much more information than just total concentration forms. At a minimum, knowledge of the filterable fractions of the constituents of interest enables calculations of the movement and trapping of the particulate-bound constituents. Much more robust calculations are possible by knowing constituent characteristics for different particle size groups, as summarized in this paper. Much better evaluations of the controllability of the pollutants, and selection of controls, is possible with this information. Clark and Pitt (2012) describe how different stormwater treatment technologies relate to the stormwater characteristics affecting treatability.

The following are the recommended levels of stormwater characteristics that should be incorporated into monitoring programs, depending on the use of the data:

1. Total constituent concentrations are obviously the most common level of effort used in stormwater monitoring efforts. This is usually conducted to meet regulatory requirements which seldom require any further portioning of the constituent characteristics;

2. At a minimum, filtered forms of the constituents of concern should be conducted in order to better understand treatability of the specific constituents, and to better support basic modeling efforts;

3. Information on concentrations associated with different particle size classes, as summarized in this 
paper, is rare. Extra costs are associated with processing the samples and for the additional analyses. Sampling and processing of samples for size fraction data are described by Pitt, et al. (2016). This information should be part of any stormwater monitoring program associated with large scale applications of stormwater controls, and associated modeling. The extra costs and efforts needed to obtain this information are small compared to the value of this information by enabling more accurate and confident stormwater management strategies. As noted in this paper, while there are some general trends associated with concentration patterns with particle size classes, these data should not be taken as being universally applicable. Site specific data will enable more robust solutions. Some models can use this level of information, while others may need to be extended to accommodate numerous particle size categories to best utilize this information; and

4. An additional set of stormwater characterization information relates to characteristics of filtered forms of the constituents. While some constituents are strongly related to particulates, others have important fractions in the filtered stormwater. In addition, some numeric discharge limits may not be met only by removing the particulate-bound material, necessitating the control of filtered pollutant forms. Morquecho (2005) demonstrated analytical schemes that enabled filtered stormwater to be effectively evaluated for treatability (ionic forms, chemical complexes, or colloids). Sorption and ion-exchange treatment of filtered stormwater (such as by chemical addition or biofilter media treatment), for example, are highly related to the form of the filtered pollutants.

Future research and development concerning stormwater characteristics and modeling using this information should include these higher levels of characterization. Model and other decision support enhancements are also needed to best use this information, especially as stormwater quality control requirements become more complex.

\section{Acknowledgments}

Much of the research reported in this paper was conducted by graduate students (listed as co-authors) as part of their Ph.D. and MSCE research in the Department of Civil, Construction, and Environmental Engineering at the University of Alabama. The funding for the research was provided by several industrial and federal agencies, which is gratefully acknowledged. The helpful comments from the manuscript reviewers are also greatly acknowledged.

\section{References}

Bathi, J. R. 2008. Associations of Polycyclic Aromatic Hydrocarbons (PAHs) with Urban Creek Sediments. Tuscaloosa, AL:The University of Alabama. Ph.D. Dissertation, Department of Civil, Construction, and Environmental Engineering.

Cai, Y. 2015. Full-Scale Up-Flo Stormwater Filter Field Performance Verification Tests. Tuscaloosa, AL: The University of Alabama. MSCE Thesis, Department of Civil, Construction, and Environmental Engineering.

Clark. S. and R. Pitt. 2012. "Targeting Treatment Technologies to Address Specific Stormwater Pollutants and Numeric Discharge Limits." Water Research 46:6715-30.

Dally, L. K., D. P. Lettenmaier, S. J. Burges and M. M. Benjamin. 1983. Operation of Facilities for Urban Stream Quality Enhancement. Seattle, WA: University of Washington. Department of Civil Engineering, Water Resources Series Technical Report (July), no. 79.

House, L. B., R. J. Waschbusch and P. E. Hughes. 1993. Water Quality of an Urban Wet Detention Pond in Madison, Wisconsin, 1987-88. Madison, WI: U.S. Department of the Interior U. S. Geological Survey, in cooperation with the Wisconsin Department of Natural Resources. USGS Open File Report 93172.

https://pubs.usgs.gov/of/1993/0172/report.pdf.

Hwang, H. M. and G. D. Foster. 2006. "Characterization of Polycyclic Aromatic Hydrocarbons in Urban Stormwater Runoff Flowing into the Tidal Anacostia River." Environmental Pollution 140:416-26.

Johnson, P. D., R. E. Pitt, S. R. Durrans, M. Urrutia and S. Clark. 2003. Metals removal technologies for urban stormwater. Water Environment Research Foundation. WERF 97-IRM-2. ISBN: 1-94339-682-3. Alexandria, VA. 701 pgs. Oct. 2003.

Lindsay, W. L. 1979. Chemical Equilibria in Soils. New York: John Wiley and Sons.

Maestre, A. 2005. Stormwater Characteristics as Described in the National Stormwater Quality Database. Tuscaloosa, AL: University of Alabama. Ph.D. dissertation, Department of Civil, Construction, and Environmental Engineering.

Maestre, A. and R. E. Pitt. 2006. “Identification of Significant Factors Affecting Stormwater Quality Using the National Stormwater Quality Database." Journal of Water Management Modeling R225-13. https://doi.org/10.14796/JWMM.R225-13.

Mahler, B. J., P. C. Van Metre and T.W. Wilson. 2005. “Parking Lot Sealcoat: An Unrecognized Source of Urban Polycyclic Aromatic Hydrocarbons." Environmental Science \& Technology 39:5560-6.

Morquecho, R. E. 2005. Pollutant Associations with Particulates in Stormwater. Tuscaloosa, AL: University of Alabama. Ph.D. dissertation, Department of Civil, Construction, and Environmental Engineering. 
Pitt, R. E. 1979. Demonstration of Nonpoint Pollution Abatement Through Improved Street Cleaning Practices. Cincinnati, $\mathrm{OH}$ : U.S. Environmental Protection Agency. EPA-600/2-79-161.

Pitt, R. E., R. Bannerman, S. Clark and D. Williamson. 2005a. "Sources of Pollutants in Urban Areas (Part 1): Older Monitoring Projects." Journal of Water Management Modeling R223-23. https://doi.org/10.14796/JWMM.R223-23.

Pitt, R. E., R. Bannerman, S. Clark and D. Williamson. 2005b. "Sources of Pollutants in Urban Areas (Part 2): Recent Sheetflow Monitoring Results." Journal of Water Management Modeling R223-24. https://doi.org/10.14796/JWMM.R223-24.

Pitt, R. E., S. E. Clark, V. K.Eppakayala and R. Sileshi. 2016. “Don't Throw the Baby Out With the Bathwater: Sample Collection and Processing Issues Associated With Particulate Solids in Stormwater." Journal of Water Management Modeling 25:C416. https://doi.org/10.14796/JWMM.C416.

Pitt, R. E. and J. McLean. 1986. Toronto Area Watershed Management Strategy Study: Humber River Pilot Watershed Project. Toronto: Ontario Ministry of the Environment.

Pitt, R. E., B. Robertson, P. Barron, A. Ayyoubi and S. Clark. 1999. Stormwater Treatment at Critical Areas: The Multi-Chambered Treatment Train (MCTT). Cincinnati, OH: U.S. Environmental Protection Agency, Water Supply and Water Resources Division, National Risk Management Research Laboratory. EPA 600/R-99/017.

Pitt, R. E., D. Williamson, J. Voorhees and S. Clark. 2005. “Review of Historical Street Dust and Dirt Accumulation and Washoff Data." Journal of Water Management Modeling R223-12. https://doi.org/10.14796/JWMM.R223-12.
Randall, C. W., K. Ellis, T. J. Grizzard and W. R. Knocke. 1982. “Urban runoff pollutant Removal by Sedimentation." In Proceedings of the Conference on Stormwater Detention Facilities, Planning, Design, Operation and Maintenance Held in Henniker, New Hampshire, edited by W. DeGroot. New York: American Society of Civil Engineers.

Rushton, B. 2006. Broadway Outfall Stormwater Retrofit Project, Monitoring CDS Unit and Constructed Pond. Brooksville, FL: South Florida Water Management District and City of Temple Terrace. W241.

Sansalone, J. J. and S. G. Buchberger. 1997a. "Characterization of Solid and Metal Element Distributions in Urban Highway Stormwater." Water Science and Technology 36 (8-9): 155-60.

Sansalone, J. J. and S. G. Buchberger. 1997b. "Partitioning and First Flush of Metals in Urban Roadway Stormwater." Journal of Environmental Engineering 123 (2): 134. https://doi.org/10.1061/(ASCE)0733-9372(1997)123:2(134).

Vignoles M. and L. Herremans. 1995. "Metal pollution of sediments contained in runoff water in the Toulouse city (in French)." In Innovative Technologies in Urban Storm Drainage (NOVATECH '95): Selected Proceedings of the 2nd NOVATECH Conference on Innovative Technologies in Urban Storm Drainage, Held in Lyon, France, 30 May-1 June, 1995, edited by B. Chocat, E. Brelot and M. Desbordes, 611-4. Organized by Eurydice 92 and Graie. International Water Association.

Zhou, J. L., T. W. Fileman, S. Evans, P. Donkin, C. Llewellyn, J. W. Readman, R. F. C. Mantoura and S. J. Rowland. 1998. "Fluoranthene and Pyrene in the Suspended Particulate Matter and Surface Sediments of the Humber Estuary, UK." Marine Pollution Bulletin 36 (8): 587-97. https://doi.org/doi:10.1016/S0025-326X(98)00036-8. 